\title{
Wikiprogress and Wikigender
}

\section{A way forward for online collaboration by Angela Hariche,} Estelle Loiseau and Philippa Lysaght

\begin{abstract}
In recent years there has been an explosion of web 2.0 technologies such as Facebook, Twitter, blogs and wikis. The world is becoming ever more connected with great technological strides which are increasingly allowing for more access to those who previously were disconnected. Web technologies are fostering mass collaboration on a scale that has never been seen before, allowing for a collective intelligence to develop on specific topics and themes. The crucial element to this participation is the openness of new web platforms, engaging everyone from policy makers to local NGOs to interested individuals. Recent technological advances are very timely as the world is also becoming more complex, and society has to face a number of global challenges that it can no longer address without connecting to others: from climate change to the financial crisis to sustainable livelihoods, these problems are global and therefore require global thinking. An important part of the problem-solving process involves the collection of information and data from diverse sources. This paper is concerned with the idea that collaborative platforms such as wikis along with advances in data visualisation are a way forward for the collection, analysis and dissemination of data across countries and societies, and presents two wiki platforms that can support such a vision: Wikiprogress and Wikigender. The paper first explains the wider movement behind the two wikis, namely the OECD-hosted Global Project on Measuring the Progress of Societies, then explores the importance of fostering collaboration and data dissemination through Wikiprogress and Wikigender. Finally, this paper concludes that collaboration is required for the shift from measuring economic production to measuring well-being to occur. Such collaboration is facilitated by web 2.0 technology.
\end{abstract}

\section{Introduction}

Societies are becoming increasingly connected thanks to advances in new technologies. Global problem-solving has been made easier through the new forms of collaboration this connectivity allows. A plethora of web 2.0 initiatives have flourished around the world, including issues like tackling climate change to solutions for sustainable development, the reduction of poverty and hunger, and decreasing the wage gap between women and men. The range of topics tackled on the Internet reflects societies increasing concern with their quality of life along with their material well-being. Leading economists studying the measurement of those factors which contribute to a person's welfare conclude that "GDP is an inadequate metric to gauge well-being over time particularly in its economic, environmental, and social dimensions, some aspects of which are often referred to as sustainability." Numerous initiatives worldwide, such as the OECD-hosted Global Project on Measuring the Progress of Societies, amongst others, have shown an interest in going beyond the mere economic prosperity of a nation - claiming that we should look beyond traditional measures such as Gross Domestic Product (GDP) in determining the well-being of societies.

Wikiprogress, the official platform of the Global Project on Measuring the Progress of Societies is a collaborative tool for measuring progress beyond GDP that exemplifies this new form of collaboration and the potential Web 2.0 technologies offer in solving global problems. It is important initially to understand the underlying movement and what "measuring progress" actually means. Examining the background of 'measuring progress' and identifying the key players will clarify the OECD's choice of a 'wiki' platform and what impact this has on the measuring progress movement.

\section{Box 1: Wikiprogress: goal and purpose}

Goal: To create a web community around the vision of measuring the progress of societies by creating a place where progress data and research articles can be loaded, visualised and analysed so good decisions about societies can be made at the local, national and international levels.

Purpose: To invite and inform all parts of the progress community, citizens and policy makers alike to the debate on progress-related initiatives by creating a robust wiki of related research and statistics. 


\section{My SIGI: Build Your Own Ranking}

Filter the ranking by region:

East Asia and Pacific | Europe and Central Asia | Latin America and the Caribbean | Middle East and North Africa | South Asia | Sub-Saharan Africa | All

Place checkmarks next to the indicators you wish to include in your gender index. Use the numbered buttons to adjust the weighting. 1 = not important, 5 = very important.

\begin{tabular}{|c|c|}
\hline$\square$ Family code & $\bigcirc_{1} \bigcirc 2 \bigcirc 3 \bigcirc 4 \odot 5$ \\
\hline$\square$ Civil Liberties & $\bigcirc_{1} \bigcirc 2 \bigcirc 3 \bigcirc 4 \odot 5$ \\
\hline$\square$ Physical Integrity & $\bigcirc_{1} \bigcirc 2 \bigcirc 3 \bigcirc 4 \odot$ \\
\hline$\square$ Son Preference & $\bigcirc_{1} \bigcirc 2 \bigcirc 3 \bigcirc 4 \odot 5$ \\
\hline$\square$ Ownership Rights & $\bigcirc_{1} \bigcirc 2 \bigcirc 3 \bigcirc 4 \odot 5$ \\
\hline
\end{tabular}

$\checkmark$ Only include countries with full data.

Calculate Ranking Reset to Defaults

\section{Map View}

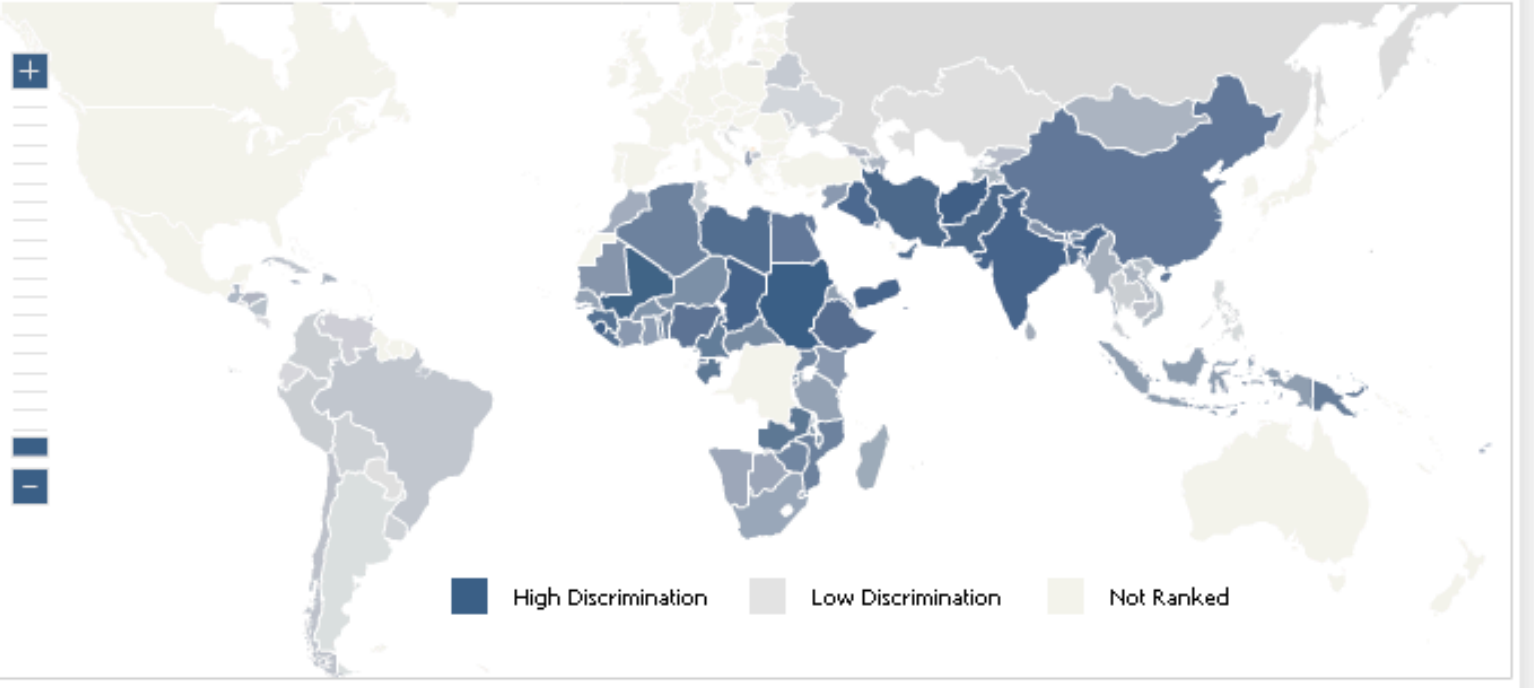

Your index at a glance: The map shows each country's ranking in your index. Move your mouse over a country to see its rank in your index and in SIGI.

Figure 1. Visualisation of the www.my.genderindex.org tool

\section{1. "Measuring Progress": an overview of the movement} For the last century the most commonly used indicator of economic performance has been GDP, also used as an indicator of national performance. It is commonly assumed that GDP growth is synonymous with progress, that a rise in GDP mirrors an increase in the quality of life and well-being of a particular society. This, however, is not the case: GDP only measures what is 'produced' - it is a very narrow economic measure that fails to take into account other elements which are important in the daily lives of citizens such as security, pollution and health care. GDP calculations include economic activities that reduce well-being such as traffic congestion, which increases fuel consumption, or those which remedy the costs of economic growth like pollution abatement.

Currently there are many organisations who are looking at new measure of progress and calling for indicators going beyond GDP to measure the well-being of individuals, of our societies and our environment. A key message from the Stiglitz-Sen-Fitoussi Commission on Economic Performance and Social Progress in 2009 shows an urgency for developing such measures, declaring that now is the time for our measurement systems to shift the focus from measuring economic production to measuring people's well-being. Furthermore, such measures of well-being should be considered and analysed within the context of sustainability.

The movement is not concerned solely with developing progress indicators but also the development of a collaborative community, working to determine how we measure progress. This kind of knowledge sharing and creation can aid statistical organisations or government by a nurturing community that encompasses diverse actors, including individuals worldwide. For this reason, the Global Project on Measuring the Progress of Societies chose to use a wiki platform, called Wikiprogress. The box below outlines the goal and 
purpose of Wikiprogress, reflecting the importance of fostering a collaborative online community.

\section{Why a wiki?}

According to the world's largest online encyclopaedia, Wikipedia, a wiki is "a website that allows the easy creation and editing of any number of interlinked web pages via a web browser using a simplified mark-up language or a text editor." In other words, a wiki is a type of web platform that allows user-generated content. The content in a wiki is created by a community of users working together to develop information on a particular subject or within a particular field. It is essentially a database of information that can be browsed, searched, created and edited.

\section{GER and GPI Pre Primary - 2009 or most recent}

Current data selection: Country [218/219] Indicator [4/4] Time [1]
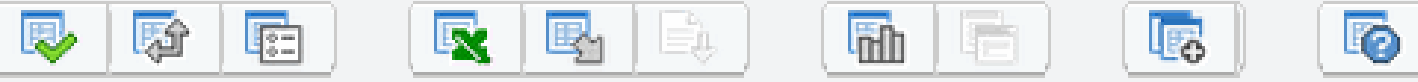

Data extracted on 18 Mar 2011 14:59 UTC (GMT) from wikiprogress statistics

\begin{tabular}{|c|c|c|c|c|c|}
\hline & \multirow{2}{*}{$\begin{array}{r}\text { Time } \\
\text { Indicator }\end{array}$} & \multicolumn{4}{|c|}{2009} \\
\hline & & $\begin{array}{l}\text { Total } \\
\Delta \nabla\end{array}$ & $\begin{array}{l}\text { Male } \\
\Delta \nabla\end{array}$ & $\begin{array}{c}\text { Female } \\
\Delta \nabla\end{array}$ & $\begin{array}{l}\text { GPI } \\
\Delta \nabla\end{array}$ \\
\hline \multicolumn{6}{|l|}{ Country } \\
\hline Afghanistan & & & & & (d) \\
\hline Albania & & 58.28 & 59.46 & 57.02 & 0.9 \\
\hline Algeria & & 23.4 & 23.36 & 23.44 & \\
\hline Andorra & & 98.53 & 99.61 & 97.35 & 0.9 \\
\hline Angola & & 40.14 & 44.91 & 35.41 & 0.7 \\
\hline Anguilla & & 94.54 & 98.66 & 90.87 & 0.9 \\
\hline Antigua and Barbuda & & 64.8 & 62.29 & 67.41 & 1.0 \\
\hline Argentina & & & & & (d) \\
\hline Armenia & & 33.3 & 31 & 35.99 & 1.1 \\
\hline Aruba & & 104.6 & 106.81 & 102.34 & 0.9 \\
\hline Australia & & 82.29 & 83.22 & 81.3 & 0.9 \\
\hline Austria & & 95.11 & 95.34 & 94.86 & 0.9 \\
\hline Azerbaijan & & 26.48 & 26.05 & 26.99 & 1.0 \\
\hline Bahamas & & & & & (d) \\
\hline Bahrain & & 58.85 & 59.11 & 58.57 & 0.9 \\
\hline Bangladesh & & & & & (d) \\
\hline Barbados & & & & & (d) \\
\hline
\end{tabular}




\section{Gender Equality in Benin Edit - Discuss}

Contents [hide]
1 Social Institutions
1.1 Family Code
1.2 Physical Integnity
1.3 Civil Liberties
1.4 Ownership Rights
1.5 In the News
1.6 Sources
2The Africa for Women's Rights Campaign
2.1 Key facts
2.2 The Campaign
2.3 Country Focus: Benin
2.4 Sources
3 The Women, Business and the Law
3.1 Where are laws equal for men and women?
3.2 Sources

\section{Social Institutions}

Benin's constitution prohibits discrimination based on race, sex and religion. Still, societal discrimination against women continues. Although Benin ratified the International Convention on the Elimination of any Form of Discrimination against Women in 1992, the convention's terms are rarely applied, as the national legal framework has not yet been harmonized with the convention. Traditional laws prevall in different spheres and, although they have no real binding power today, they still justify the existence of customs that often discriminate against women. While the Code of Persons and Family (drafted by the government in 1990) was voted upon and promulgated by the country's president in 2004 , it is not effectively enforced and therefore largely unknown by the public.

\section{Figure 3 Preview of a country note on Benin.}

\section{What are Wikiprogress and Wikigender?}

Wikiprogress (www.wikiprogress. org) and Wikigender (www. wikigender.org) are interactive communication tools that centralise information, data, initiatives, publications, events, media coverage and research networks that are all part of the international movement to look beyond GDP in measuring the progress of societies. Wikiprogress brings together many dimensions of progress (ecosystems condition, human well-being, economy, governance and culture). Wikigender specifically looks at gender equality and women's empowerment, with a particular focus on developing countries.

\subsection{Wikiprogress}

Wikiprogress is the official online platform for the OECD-hosted Global Project on Measuring the Progress of Societies. It was announced and presented in beta version at the 2009 OECD World

Forum in Busan, Korea. Since then, Wikiprogress has grown significantly: it now has over 450 active members, over 840 articles and over 8,400 unique visitors a month.

The Global Project is a partnership project that aims to develop a large "network of networks" of experts in the field of research into progress, including academics, civil society and NGOs, to work together on gathering information and data related to measuring progress. The wiki platform facilitates this collaboration and

But wikis, blogs and other Web 2.0 technologies are much more than simply tools to facilitate collective contribution. They are the force behind a new era of mass collaboration and participation that is changing the way we deal with global issues. Information is now being created, updated, discussed and made public by an engaged community from all over the world. Rather than an expert or team of experts assembling information on a particular topic, access is now open to worldwide resources in developing knowledge around a subject. A recently coined term, "wikinomics", defines this movement as "the new force that is bringing people together on the net to create a giant brain" . Openness and collaboration using Web 2.0 functionality provides for a democratisation of innovation. The speed, scope and manner in which innovation occurs has radically and rapidly changed since Web 2.0 tools, including wikis, can provide "low-cost collaborative infrastructures... in ways only large corporations could in the past". Hence, the collective knowledge and ingenuity of individuals and businesses is fully exploitable. participation, ensuring the movement is inclusive and ever-growing

It is not only the community that makes Wikiprogress effective,

but also the content diversity. So far, the term "information" has been used to cover all of the content on Wikiprogress, but to understand the extent of the information available, it can be divided into key sections. These divisions will change and develop over time as the Wikiprogress community expands and enriches the content.

- Information by topic - Information on a particular dimension of progress (e.g. peace, trust, pollution) is gathered in one article with internal links to related pages, external links to relevant organisations and a list of reports and publications for further reading.

- Information by country - Each country has its own article listing the main national and regional initiatives. The country articles also link to relevant data and list country-specific publications and reports.

- Progress initiatives - Initiatives from around the world that gather information and/or data on measuring progress have their own article including the aim, function and background of the 
particular group. These articles also contain links to relevant data, videos of presentations and speeches, publications and reports. There are many different initiatives, some working within specific dimensions of progress and others working across all dimensions. - Progress publications - Wikiprogress highlights reports and papers as they are published, on the condition that they are not for sale. The reports can be searched by topic or by country.

- Progress-related events - Events are held worldwide focusing on different dimensions of progress, the measurement of progress and the development of better indicators.

- Media coverage - A good measure of a movement's success, and certainly a good way to monitor the development of the movement, is by tracking what the media is covering and examining media treatment of key players and events. The Wikiprogress Community Portal gathers news items and blog posts on the movement as they are released.

- Finally, one of the most significant aspects of Wikiprogress: progress-related data. This component of Wikiprogress is detailed in the last part of this paper which focuses on data.

\subsection{Wikigender}

Wikigender is an online platform that was developed by the OECD Development Centre and launched on 8 March 2008, on the occasion of International Women's Day. It is the first wiki platform hosted by the OECD, and acted as a pilot project before the launch of Wikiprogress. Wikigender is therefore naturally linked to Wikiprogress. Furthermore, measuring the progress of societies without paying particular attention to women, who represent more than half of the population, would not be offering a comprehensive picture.

Since its launch, Wikigender has seen its community grow exponentially: it now consists of over 960 registered users coming from around 170 countries and comprises more than 1,120 articles. Added to these statistics, the site recently attracted over 15,000 visits during the course of a single month, a number that increases monthly.

Wikigender, is an interactive online tool that focuses on gender equality issues, as well as on data and measurements in the area of gender equality. Like Wikiprogress, the site allows its registered users to add, edit or discuss information and/or data provided on the site. The platform therefore easily allows for up-to-date and accurate information

The information available on the site is also organised by topic/ category, country, organisations/initiatives, publications, events and statistics. It also has a community portal that lists media coverage on timely gender equality issues.

In terms of specific projects, Wikigender has started to work with Paris-based universities, engaging students to add content to the site and benefitting from the networking opportunities of Wikigender. This programme, called "Wikigender University", will be extended to selected universities worldwide, further enriching Wikigender with content related to the measurement of progress made in gender equality, and at the same time empowering students through information-sharing and capacity-building in the area of information technology.

Similarly, "Wikigender Impact" is project under development examining the establishment of a bridge between the community of donors and policymakers and the community of practitioners on the ground, by developing a database of case studies and becoming a clearinghouse for funders and those seeking financial support for projects.

\subsection{The importance of understanding data}

Developing better indicators and awareness is not enough. We also need to ensure that the measures become widely used, and widely understood - not only by statisticians, but by all those interested in societal progress.

Visualising data in a time series allows us to see the impact of the progress - or regress - according to the particular data set. It also makes the data easier to understand, so that a wider audience has access to understanding its significance. There follows an introduction to the data presentation and visualisation tools available on the wikis.

\section{a) Wikiprogress.Stat}

It is one thing to have good statistics. It is another to make sure these statistics are used. New Information Communication Technology (ICT) tools have the ability to not only make data easily available for anyone with an internet connection, but also allow for the data to be presented in a way that can be understood. Both Wikiprogress and Wikigender have developed ways in which data could be better understood.

Wikiprogress has developed a statistical tool that facilitates the task of data collection, analysis and dissemination: Wikiprogress.Stat. Data from a variety of sources is progressively populating this database of progress indicators and is being used to support articles in both Wikiprogress and Wikigender. The database also complies with the wiki model; users can upload their own data and metadata, therefore democratising the process of data collection. Through Wikiprogress. Stat, anyone can upload data and access the information. After a quality control procedure, the data will be uploaded into Wikiprogress.

The overall aim of Wikiprogress.Stat is to create a robust database of progress indicators for a wide range of regions, over the longest possible time-scale. There are currently over 100 data sets in the Wikiprogress.Stat database, including The Global Peace Index, World Bank Economic Indicators, and The World Database of Happiness, amongst others.

Tables, graphs and charts created on Wikiprogress.Stat will then be used in articles on Wikiprogress to illustrate how different progress dimensions have impacted the well-being of particular societies.

Additionally, the OECD is working with Norrköping Communicative Visual Analytics (NComVA) on the implementation of a new data visualisation tool, explorer, to allow users to create stories using data sets in Wikiprogress.Stat and visualise the material in an animated time series. Each visualised story, a vislet, is embeddable in Wikiprogress articles and on external websites, blogs, etc.

Furthermore, the explorer will be an embeddable tool not only in wiki articles, but also in external blogs and online journals. This will broaden the scope of discussions and reports that can use the visualisation to assist in explaining and/or supporting ideas and arguments on social progress.

\section{b) Wikigender}

Gender equality datasets are also uploaded through Wikiprogress.Stat. Apart from presenting OECD data such as the Gender, Institutions and Development Database (GID-DB) or the Social Institutions and Gender Index (SIGI), Wikigender links to www.my.genderindex.org, a tool allowing users to manipulate SIGI data for their own analyses.

Furthermore, any new gender-related data included in Wikiprogress. Stat automatically appears on Wikigender. This is the case, for example, of UNESCO data accompanying the 2010 Global Education Digest.

Finally, Wikigender also presents information on the gender equality situation by country. Each country page includes quantitative and qualitative data from the SIGI as well as data from additional sources to offer a more comprehensive view of gender equality in a given country. For example, SIGI data examines discrimination against women from the point of view of social norms, cultural values, and traditions. But some country notes also cover data from Wikigender partners the World Bank and the International Finance Corporation (IFC), looking 
at laws and regulations affecting women's prospects as entrepreneurs and employees. More data will also soon be added, for example, examining women's and men's access to land. Wikigender will also continue to collaborate with other organisations in order to give the most accurate and comprehensive picture of gender equality across countries. Such an approach gives the advantage to the user to find information on one topic, in one country, looked at from various angles and perspectives. .

The above tools offer various entry points to the data, allowing any site users to access, upload, manipulate, or analyse data and draw analytical conclusions. Both Wikiprogress and Wikigender have large and diverse audiences which include policymakers, non-governmental organisations, think tanks, international organisations, statistical offices, students, academics, practitioners, and donors.

\section{Conclusion}

The movement to look beyond economic indicators in measuring well-being can be successful by working society-wide. In order to measure what is important to societies, a collaborative effort is required. Currently, wikis are the correct web platform for collective brainstorming, collaborative problem-solving and for centralised global efforts and initiatives working towards a common goal. In this regard, Wikiprogress is the appropriate tool for the successful collection, analysis and dissemination of information across countries and societies, as Wikigender is similarly for collaboration and knowledge sharing in the area of gender equality and gender statistics.

We invite members of the IASSIST community to join the community and participate in the ongoing debates on www.wikiprogress.org and www.wikigender.org. We are always looking for new ways to collaborate with different organisations. If you are interested in either of these initiatives, we invite you to contact us at info@wikiprogress.org.

\section{Notes}

1.Hariche, Angela, Estelle Loiseau, et Philippa Lysaght. «Wikiprogress and Wikigender: a way forward for online collaboration.» 2010 IASSIST Conference. Ithaca, 2010.

2. Organisation for Economic Co-operation and Development (OECD). Wikiprogress. 2010. http://wikiprogress.org/.

3.Organisation for Economic Co-operation and Development (OECD). Wikigender. 2010. http://wikigender.org/.

4. Stiglitz, Joseph E., Amartya Sen, et Jean-Paul Fitoussi. Report by the Commission on the Measurement of Economic Performance and Social Progress. PDF, Paris: Commission on the Measurement of Economic Performance and Social Progress, 2009. Pg. 8.

5. Ibid.

Wikipedia contributors, "Wiki,"Wikipedia, The Free Encyclopedia, http://en. wikipedia.org/w/index.php?title=Wiki\&oldid=411214821 (accessed February 10, 2011).

7.Tapscott, Don, et Anthony D. Williams. Wikinomics: How Mass Collaboration Changes Everything. New York: Portfolio, 2006

7. Williams, Anthony D. «Wikinomics and the Era of Openness: European Innovation at a Crossroads.» The Lisbon Council e-brief issue 05/2010. 2010. http://www.lisboncouncil.net//index. php?option=com_downloads\&id $=316$.

8. Organisation for Economic Co-operation and Development (OECD). Wikiprogress.stat. 2010. http://wikiprogress.stat/.

9. Wikigender.org contributors, "The 2010 Global Education Digest: Datasets,"Wikigender.org, http://www.wikigender. org/index.php?title=The_2010_Global_Education_Digest:_ Datasets\&oldid=15654 (accessed February 10, 2011).

10. Other Wikigender partners; América Latina Genera, Destatis, FAO, FIDH and Africa for Women's Rights Campaign, IPS Genderwire, La
Halde, Mujeres del Muldo + 2nd International Documentary Festival on Gender, United Nations Womenwatch, UN-INSTRAW 